\title{
Compras públicas e promoção do desenvolvimento local
}

Eduardo de Lima Caldas e Raquel Sobral Nonato

\section{Introdução}

O objetivo deste trabalho é apresentar as compras públicas governamentais como ferramenta estratégica de apoio ao desenvolvimento local. Trata-se de identificar o poder de compra do governo como uma estratégia de reconectar o consumo (governamental) e a produção (local).

A experiência escolhida para a referida análise é a de Apucarana (PR), em decorrência da ousadia de lançar mão de tal estratégia, o que exigiu intenso esforço dos gestores de políticas públicas locais, tanto do ponto de vista da confecção legal (produção legislativa) e logística (organização interna para recepção e distribuição dos produtos a serem consumidos), quanto do ponto de vista político (articulação com os produtores locais).

O artigo está organizado em quatro partes, além desta introdução e das considerações finais: nota metodológica; compras públicas como estratégia para o desenvolvimento local; o caso de Apucarana; aprendendo com a experiência.

$\mathrm{Na}$ primeira parte, são apresentadas as diretrizes metodológicas que orientaram o presente estudo. $\mathrm{Na}$ segunda parte, denominada "Compras públicas 
como estratégia para o desenvolvimento local", aborda-se a potencialidade do uso do poder de compra dos governos para a dinamização da economia no nível local. $\mathrm{Na}$ terceira parte, por sua vez, apresentamse os resultados do estudo de caso sob a perspectiva dos atores e dos arranjos institucionais. Finalmente, são colhidas as impressões da realização do estudo de caso, de modo a destacar as oportunidades e os desdobramentos possíveis.

\section{Nota metodológica}

A metodologia desta pesquisa está amparada em um estudo de caso com visita de campo, observações livres e um conjunto de entrevistas semiestruturadas. $\mathrm{O}$ estudo de caso único em detrimento de casos comparados justifica-se pela relevância do caso selecionado. O Município de Apucarana foi o primeiro Município a articular, por meio de políticas públicas municipais, o fortalecimento de assentamentos de agricultores familiares e o uso do poder de compra dos governos locais. Nesse aspecto, portanto, a escolha do Município de Apucarana (PR) se deu, primordialmente, pelo aspecto precursor e inovador da experiência que, aos poucos, foi se institucionalizando em diversos locais no Brasil.

Segundo Yin (2005), o estudo de caso busca "investigar um fenômeno contemporâneo, no contexto da vida real, especialmente quando as fronteiras entre o fenômeno e o contexto não estão perfeitamente delimitadas" (2005, p. 13). Ao discutir a pertinências dos estudos de caso com "experiências únicas", Yin (2005) afirma que essas situações se justificam quando a experiência é ilustrativa. No caso de Apucarana (PR), a prática desenvolvida é ilustrativa no que se refere ao mecanismo de compras públicas, visando ao desenvolvimento local.

Os roteiros de entrevistas aplicados na pesquisa em questão foram inspirados no Programa Gestão Pública e Cidadania (PGPC), da Fundação Getúlio Vargas (FGV). As entrevistas foram realizadas no segundo semestre de $2010^{1}$. Trata-se de um roteiro de entrevistas aplicado a múltiplos atores, com o objetivo de conhecer a política pública local a partir do olhar dos atores envolvidos. Assim, foram entrevistados o Secretário Municipal de Educação, uma servidora pública responsável pelo Programa Municipal de Alimentação Escolar, duas merendeiras, um produtor e uma produtora rurais, e uma servidora pública responsável pelo escritório do Instituto Paranaense de Assistência Técnica e Extensão Rural (Emater-PR) no município de Apucarana. As entrevistas foram realizadas no ambiente de trabalho de cada ator entrevistado, de tal forma que também foi possível fazer "observações livres" sobre o tema em tela. Além disso, foi possível "conversar" informalmente com professores, funcionários das escolas (secretários/as e inspetores/as de alunos), além de alunos e pais de alunos, no ambiente escolar.

\section{Compras públicas como estra- tégia para o desenvolvimento local}

As compras públicas guardam forte relação com a ação do Estado capaz de ativar dispositivos para dinamizar a economia local, uma vez que movimentam recursos estimados em 10\% do PIB brasileiro (CATTANi, 2010).

Apesar disso, por muito tempo as iniciativas para a promoção do desenvolvimento local estiveram focadas tanto em estratégias que reduzissem a despesa das famílias e, assim, garantissem um aumento 
real da renda líquida familiar (agricultura urbana, aproveitamento de alimentos, entre outras), quanto em estratégias que organizassem a oferta de produtos (formação, capacitação, oferta de crédito, entre outras). Contudo, poucas foram as experiências que propuseram ferramentas e adotaram estratégias para induzir o desenvolvimento local a partir da organização da demanda.

O desenvolvimento local é um tema controverso no debate internacional. Tratase, na verdade, de um campo em disputa, em que conceitos, teorias e metodologias muitas vezes se sobrepõem, tantas vezes se complementam, e outras vezes se contradizem.

Há uma corrente de pensamento que interpreta o desenvolvimento local como a expressão de um novo arranjo industrial "pós-fordista" (BENKo e LipieTz, 1994).

Outra corrente interpretativa percebe o desenvolvimento local não apenas como reflexo da reorganização internacional do trabalho/capital, mas como resultado de dinâmicas "locais" próprias (BECATTINI, 1994).

Uma terceira abordagem para compreender o desenvolvimento local parte da existência de fatores de produção disponíveis no território, suas especificidades, as possibilidades de alocação conjunta dos referidos fatores disponíveis, e os mecanismos que transformam fatores e "recursos territoriais" em "ativos territoriais específicos” (Pecqueur, 1989; Pecqueur, 2005).

Outra forma de interpretar o desenvolvimento local parte da ideia de desenvolvimento local de base, ou "desenvolvimento de baixo para cima". Para esses autores, a sociedade civil, e não o Estado e tampouco as organizações voltadas para o mercado, é o principal ator capaz de construir um projeto local para o desenvolvimento e de colocá-lo em marcha. O pro- cesso de desenvolvimento desencadeado pelas organizações de base contagia a esfera política e produz efeitos de ampliação tanto de apropriação da renda quanto, e principalmente, de ampliação de direitos e participação política (SANTOS E RodrígueZGaravito, 2006; Hirschman, 1984).

Finalmente, há uma interpretação que associa desenvolvimento local a desenvolvimento econômico comunitário (Boothroyd e Davis, s/d).

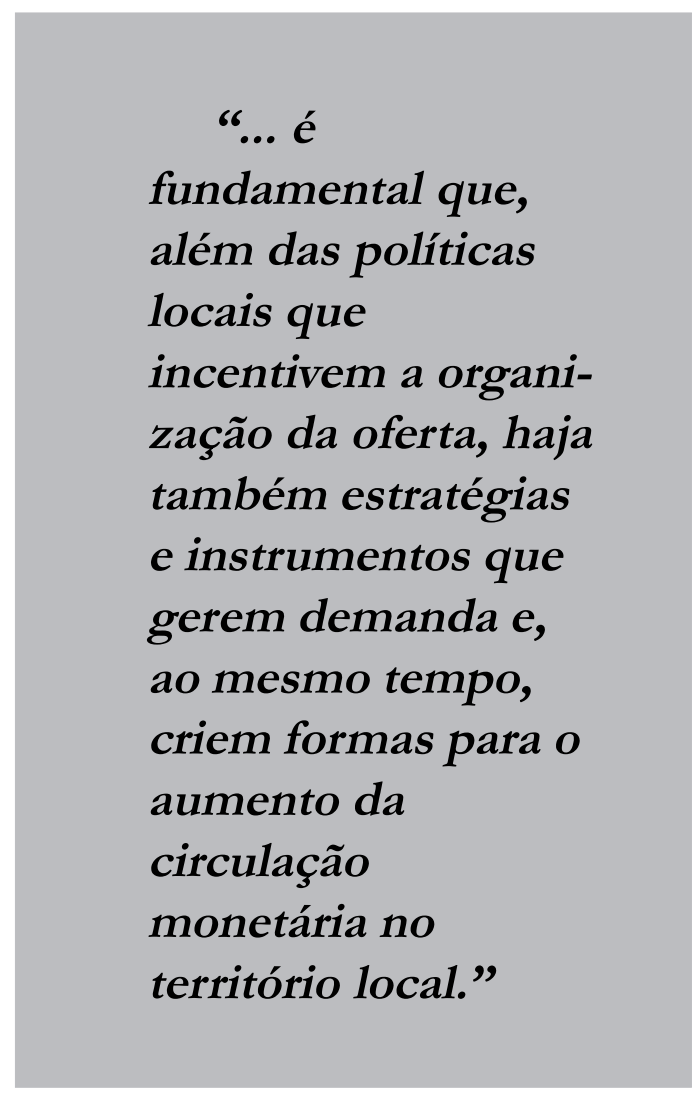

No Brasil, a valorização do local como instância privilegiada para executar políticas públicas de desenvolvimento remonta aos anos 1970 (Martins, Vaz e Caldas, 2010). A ideia de desenvolvimento local, no caso brasileiro, associa intensamente a dimensão econômica com a dimensão política. Desde meados dos anos 1970, pode-se observar a predominância de diferentes 
tipos de instrumentos e estratégias de políticas públicas locais.

Entre 1976 e 1988, destacaram-se experiências focadas no território, preocupadas com a promoção da participação efetiva da comunidade e com as estratégias de alternativas econômicas capazes de reduzir a despesa das famílias (descompressão orçamentária) e, assim, garantir um aumento real da renda líquida familiar (agricultura urbana, aproveitamento de alimentos, entre outras). Nesse período, é possível identificar um número reduzido de experiências, tais como Lages - SC (Alves, 1980) e Boa Esperança - ES (SouzA, 1982), capazes de se tornarem expoentes de um modo democrático de gestão.

Entre 1989 e 1992, observou-se o fortalecimento institucional dos Municípios, muito embora não se tenham observado experiências inovadoras em termos de gestão pública municipal. Entre 1993 e 2004, observaram-se, ao mesmo tempo, dois estilos diferentes de políticas públicas: o "hobbesianismo municipal" (Melo, 1996) e o "experimentalismo difuso" (SILVEIRA, Bocayuva e Zapata, 2001).

Em contexto adverso, do ponto de vista econômico, muitos Municípios passaram a fazer a gestão da crise por meio de políticas públicas isoladas e de incentivos fiscais, com intuito de atrair empresas (principalmente indústrias) como mecanismo de minimizar os efeitos do desemprego. Esse estilo de política isolada, desarticulada e competitiva entre municípios ficou conhecido como "hobbesianismo municipal” (Melo, 1996).

No mesmo período, foi possível observar a construção de diferentes instrumentos e estratégias de políticas públicas que se tornaram "vitrine" tanto para outros municípios quanto para outros níveis de governo (estaduais e nacional). Dentre os instrumentos, destacam-se: cursos e escolas de formação profissional; instalação de centros tecnológicos, agências de desenvolvimento regional, minidistritos industriais; formação de arranjos produtivos locais (APL); constituição e fortalecimento de cooperativas, grupos de economia solidária, autogestão, agroecologia; inserção de municípios na rede de comércio justo e solidário, criação de bancos populares com microcrédito e moedas sociais (MARTINS, Vaz e Caldas, 2010). Essa miríade de experiências difusas no tempo e no espaço passou a ser chamada de "experimentalismo difuso" (Silveira, Bocayuva e ZAPATA, 2001).

Apesar dessa abundância de experiências, pouco se observou em termos do uso de poder de compra dos governos.

Assim, organizar a oferta de produtos por meio de apoio ao desenvolvimento tecnológico, à melhoria da mão de obra, e à assistência técnica, embora necessário, é insuficiente. É preciso organizar a demanda e isso se faz por meio da gestão dos gastos públicos: "gastos criam demanda, quaisquer que sejam [os gastos]" (Krugman, 2012).

As alterações na demanda efetiva, advinda tanto da expansão da massa salarial quanto do aumento das atividades de exportação ou das despesas públicas, têm efeito multiplicador sobre a renda local: seja um efeito direto decorrente do aumento do consumo das famílias; seja um efeito indireto, que estimula a produção de outros setores (Dillard, 1976; Carvalheiro, 1987; SCHOr, 1988; Krugman, 2012).

De acordo com a teoria keynesiana, "os gastos novos no consumo do governo, tais como os pagamentos de auxílios e os subsídios para a educação, podem ser considerados como investimentos em seres humanos" (Dillard, 1976), bem como obras ou mesmo "gastos inúteis" podem 
enriquecer a comunidade. O gasto público tem efeito multiplicador, fazendo com que seus fornecedores aumentem, cada qual, seus níveis de consumo e gerem mais empregos (Dillard, 1976; Carvalheiro, 1987; SCHOR, 1988; KRUGMAN, 2012).

Essa abordagem é herdeira da tradição keynesiana, muito embora Keynes (18831946) jamais tenha tratado de desenvolvimento local.

A dinamização da demanda efetiva no nível local, assim como ocorre com as economias nacionais, está intrinsecamente ligada ao gasto (custeio) e ao investimento do setor público.

Assim, é fundamental que, além das políticas locais que incentivem a organização da oferta, haja também estratégias e instrumentos que gerem demanda e, ao mesmo tempo, criem formas para o aumento da circulação monetária no território local.

Esforços dessa natureza são escassos e foram realizados inicialmente, no âmbito estadual, no Estado de São Paulo, no Governo Montoro (São Paulo, 1987a; São Paulo, 1987b; Alves, 1985), e no Estado do Ceará, no Governo Ciro Gomes (Tendler, 1998). Também há registros de importantes esforços de organização da demanda no âmbito municipal, como é o caso de Santos (SP), por meio da Operação Praia Limpa criada na gestão do prefeito David Capistrano, e Mauá (SP), por meio das frentes de trabalho (Dowbor, 2004).

Nesse contexto de organização da demanda como estratégia para o desenvolvimento local, o caso de Apucarana (PR) tem importância ímpar porque foi capaz, por meio da política de alimentação escolar, de organizar a oferta estruturando e capacitando pequenos produtores familiares; e de induzir à demanda, por meio do uso do poder de compra do governo, viabilizada com a promulgação de uma lei municipal (Apucarana, Lei Municipal no 143/06) que priorizou o pequeno produtor familiar como fornecedor da Prefeitura. Trata-se, portanto, de uma experiência local, que sintetiza esforços anteriores difusos no tempo e no espaço.

\section{O uso do poder de compra do governo: o caso de Apucarana}

O Município de Apucarana (PR) possui 121.290 habitantes (segundo o Instituto Brasileiro de Geografia e Estatística IBGE, em 2009), distribuídos em 558.388 $\mathrm{Km}^{2}$, ou seja, $210 \mathrm{hab} / \mathrm{km}^{2}$ (segundo o Instituto Paranaense de Desenvolvimento Econômico e Social - Ipardes, em 2009). Do ponto de vista geográfico, Apucarana está localizada na região norte do Paraná (região norte central paranaense). O Município é banhado por três bacias hidrográficas (Rio Pirapó, Biguaçu e Jaboti) e, por conta disso, é território estratégico para o abastecimento das cidades vizinhas e das regiões metropolitanas limítrofes. Se, por um lado, isso é vantagem, por outro implica grande responsabilidade dos gestores públicos no que diz respeito ao desenvolvimento sustentável, não apenas da cidade, mas também do entorno, tanto para essa geração quanto para gerações futuras. Não é por menos que se pode observar no Município o desenvolvimento de vários projetos e programas no campo do desenvolvimento econômico mais tradicional e, ao mesmo tempo, uma série de programas e projetos no campo do meio ambiente (gestão dos resíduos sólidos e, principalmente, gestão das bacias e preservação das matas ciliares).

No interstício desses dois campos (desenvolvimento econômico tradicional e meio ambiente), existe o que se pode 
chamar de "atividades do meio rural, da roça”, que, por um lado, requerem tecnologia para manter-se ou tornar-se competitivas, mas, por outro, requerem cuidado redobrado em termos de manejo sustentável das nascentes.

Do ponto de vista das atividades econômicas, o Município concentra suas ações no setor industrial e agrícola, além do de comércio e de serviços, com predominância da área de saúde, tanto pública quanto privada.

Apesar da predominância do setor têxtil, fundamentalmente relacionada à confecção de bonés, o Município não é refém do referido setor. Há mais de 50 atividades em diferentes setores desenvolvidas no Município.

No setor rural, além do tradicional plantio do café realizado desde os anos 1950 e da soja mais recentemente, há famílias que cultivam uva, hortifrutigranjeiros, milho e seus derivados (ração animal), principalmente no regime de pequenas propriedades familiares.

Especificamente para esse setor, quais seriam as estratégias para o fortalecimento da agricultura familiar? São muitas as possibilidades, desde a criação de pequenos assentamentos, como as Vilas Rurais implementadas pelo governo estadual desde meados dos anos $1990^{2}$, passando pelos cursos de formação, tanto de caráter mais técnico quanto de caráter mais gerencial, até políticas de concessão de crédito.

No caso específico de Apucarana, além de lançar mão dessas ferramentas por meio de um conjunto de parcerias seja com o governo do Estado, seja com o Governo Federal, há uma iniciativa que merece destaque. Trata-se do uso do poder de compra do governo como ferramenta para estimular o desenvolvimento local.
Desde 2006, o governo municipal compra os gêneros alimentícios (para atender à política de alimentação escolar) dos agricultores familiares locais. Do ponto de vista legal, a Câmara Municipal de Apucarana aprovou lei específica (Apucarana, Lei Municipal no 143/06) que institui “a dispensa de processo licitatório para aquisição de produtos agropecuários produzidos por agricultores familiares participantes do Programa Nacional de Fortalecimento da Agricultura Familiar (Pronaf)".

Deve-se dizer que, além da articulação política que viabilizou a aprovação da lei no âmbito da Câmara Municipal, havia também amparo legal nacional.

Segundo a própria Lei Municipal $\mathrm{n}^{\mathrm{o}}$ 143/06:

A aquisição de produtos agropecuários destinados à elaboração da merenda escolar dos alunos da Rede Municipal de Ensino de Apucarana, produzidos por agricultores familiares, poderá ser realizada com dispensa de licitação conforme autoriza o $\int 2^{\circ}$ do Artigo 19 da Lei no 10.696, de 02 de julho de 2003 (Apucarana, Lei Municipal no 143/06).

A Lei Federal no 10.696, que ampara a legislação municipal, diz que o Programa Nacional de Aquisição de Alimentos tem a finalidade de incentivar a agricultura familiar, e expressa literalmente que:

O Programa de que trata o caput será destinado à aquisição de produtos agropecuários produzidos por agricultores familiares que se enquadrem no Programa Nacional de Fortalecimento da Agricultura Familiar (Pronaf), ficando dispensada a licitação para essa aquisição desde que os preços não sejam superiores aos praticados 
nos mercados regionais (BRASIL, Lei $\mathrm{n}^{\mathrm{Q}}$ 10.696, \ $2^{\circ}$ do artigo 19).

Deve-se dizer que, na ocasião da implementação do Programa Municipal de Alimentação Escolar em Apucarana, ainda não havia a prática de adquirir gêneros alimentícios de produtores locais e de articular a demanda do poder público pelos referidos gêneros com a oferta de produtores locais ${ }^{3}$.

\section{Alimentação Escolar}

Enquanto muitos municípios terceirizam a gestão da alimentação escolar, o Município de Apucarana prova que é possível fazer uma gestão pública eficiente e de qualidade na área da alimentação escolar, envolvendo os servidores e gerando renda para os agricultores familiares locais.

O Centro de Alimentação Escolar executa as seguintes operações para levar a cabo a política de alimentação escolar: compra, distribuição, qualificação e acompanhamento da produção da alimentação escolar para 10.892 alunos distribuídos em 20 creches e 38 escolas da rede municipal, ou seja, de todas as unidades escolares da rede pública municipal.

De acordo com Relatório da Secretaria Municipal de Desenvolvimento Humano da Prefeitura do Município de Apucarana, em 2010, eram fornecidas 36.502 refeições por dia (APUCARANA, 2010), a um custo total diário por aluno de $\mathrm{R} \$ 1,16$.

A compra dos itens não perecíveis é realizada uma vez por ano, utilizando o mecanismo de pregão eletrônico. O processo de compra é simples. Primeiro, criase o cardápio a partir das necessidades nutricionais das crianças, com o apoio de uma nutricionista, responsável pela alimentação escolar, e de suas auxiliares. Em seguida, elabora-se o edital. Para a compra de itens perecíveis são realizadas chamadas públicas. Atualmente participam das chamadas públicas 38 produtores rurais familiares. Além disso, a Central de Alimentação Escolar também é responsável pela aquisição de alimentos por meio do Programa Compra Direta. Os produtos são entregues por 103 produtores rurais familiares cadastrados, e distribuídos para sete creches (além das 20 já enunciadas), 15 escolas (além das 38 citadas) e 12 entidades beneficentes.

O produtor entrega o produto e assina uma nota de entrega. É a partir dessa nota de entrega que se procede ao pagamento. Nas escolas, junto com o produto, o Diretor assina uma nota de recebimento. Tudo muito simples e extremamente eficiente. Desse modo, tem-se, por um lado, o controle de estoque e, por outro, o controle público e a possibilidade de

\section{Quadro 1: Estrutura de custo da alimentação escolar, segundo itens (2010)}

\begin{tabular}{|l|c|}
\hline Itens da Estrutura de Custo & Valor Diário (em R\$) \\
\hline Gêneros Alimentícios & 0,82 \\
\hline Funcionários & 0,30 \\
\hline Despesas Gerais & 0,04 \\
\hline Total (Aluno/dia) & $\mathbf{1 , 1 6}$ \\
\hline
\end{tabular}

Fonte: Relatório "Quantitativos da Educação Integral em Apucarana". Apucarana, 20 de março de 2010 . 
checagem dos produtos recebidos e distribuídos.

\section{As merendeiras}

As merendeiras são capacitadas e valorizadas em seus afazeres. São realizadas três capacitações por ano. Trata-se de "batepapo" nos polos educacionais, nos quais as merendeiras trocam receitas econômicas, discutem com as nutricionistas sobre os valores nutricionais dos pratos propostos, aprendem e ensinam a fazer "receitas econômicas", trocam ideias e experiências a partir de queixas e sugestões de diretores, alunos e pais de alunos. Também há aulas práticas na cozinha da Faculdade de Nutrição e palestras com informações sobre higiene pessoal, combate e prevenção de incêndios, autoestima, vida saudável, entre outras.

Qual a indumentária adequada para uma merendeira? É o bom senso: sapato de segurança, touca, jaleco e mãos bem cuidadas, lavadas com frequência com água corrente e sabão, e unhas cortadas e sem esmalte.

As merendeiras da Escola Municipal de Ensino Fundamental (Emef) Karel Kober e da Emef Edson Giacomini confirmam a importância dos encontros e da formação permanente, das dicas, da troca de experiência, e têm orgulho de mostrar os equipamentos da cozinha (forno, fogão, geladeira, frigorífico, entre outros), os apetrechos e o estoque de alimentos criteriosamente organizado.

\section{Produtores rurais: do rótulo à propriedade}

No estoque do Departamento de Alimentação Escolar da Prefeitura de Apucarana é possível observar as datas de validade, bem como a origem de cada um dos produtos. A partir do rótulo da embalagem, é possível refazer a trajetória do produto. De onde vem esse produto? Quem o produz? Seria possível comprovar que esses produtos são fruto da agricultura familiar?

Os produtos são efetivamente fruto da agricultura familiar local. Em visita a um produtor de suco de uva, em sua propriedade, foi possível conhecer o processo produtivo e buscar compreender o processo de venda do seu produto e sua relação com o "mercado institucional". Percebeu-se, a partir da referida visita, que o processo de venda é simples.

Em seguida, foi a vez de conhecer uma produtora de pão artesanal e fornecedora para a política de alimentação escolar. A explicação foi semelhante. Para os dois produtores, o papel da Empresa de Assistência Técnica e Extensão Rural (Emater) e da parceria dessa com a Prefeitura é fundamental. Assim, a construção do "mercado institucional" para garantir o abastecimento do Programa de Alimentação Escolar é construção coletiva, na qual a Emater e a Prefeitura cumprem papel de extrema relevância. $\mathrm{O}$ mercado se constrói a partir da existência dos assentamentos e dos agricultores familiares, efetivos produtores de gêneros alimentícios; da Emater, responsável pelo apoio e capacitação técnica dos produtores; da Prefeitura, demandante dos produtos gerados pela agricultura familiar, articuladora dos atores envolvidos com o sistema produtivo de gêneros alimentícios para alimentação escolar, e proponente da lei que ampara a institucionalização do referido mercado; e da Câmara Municipal que, por meio de sua autonomia em legislar sobre "assuntos de interesse local", aprovou a Lei no 143/06, que institui "a dispensa de processo licitatório para aquisição de produtos agropecuários produzidos por agricultores familiares participantes do Programa 
Nacional de Fortalecimento da Agricultura Familiar (Pronaf)".

Conjunto de ações para a agricultura familiar

A Prefeitura Municipal de Apucarana, desde meados dos anos 1990, tem ações que colaboram com o fortalecimento da agricultura familiar. Atualmente o que se observa é uma ação conjunta para enfrentar o que podemos chamar de linhas de problemas que afligem o produtor rural familiar: crédito, assistência técnica e comercialização.

A questão do crédito, desde 1996, vem sendo enfrentada principalmente por meio do Pronaf, implementado pelo Governo Federal. A assistência técnica é garantida pela Emater e por empresas semelhantes. $O$ que faltava era um programa ou um conjunto de projetos que apoiasse a comercialização do produto rural advindo das pequenas propriedades familiares. Desde 2006, o Município de Apucarana está autorizado por lei municipal a dispensar do processo licitatório agricultores familiares que fornecem gêneros alimentícios para a alimentação escolar e para programas municipais destinados ao combate à fome e à promoção da segurança alimentar e nutricional.

Outras iniciativas para induzir a demanda são as seguintes: Feira Permanente dos Produtores; feiras semanais; e feiras eventuais promocionais de venda, tais como a Feira do Sabor e a Feira da Agricultura Familiar (Agrofam), que se preocuparam em atrair produtores e consumidores.

Para realização das feiras e especificamente das feiras eventuais e promocionais, a Prefeitura de Apucarana disponibilizou espaço para praça de alimentação, Feira de Sabores do Paraná, exposição de animais, exposição de equipamentos e maquinários, Fazendinha do Colégio Agrícola, exposição de carros antigos, exposição de motos e feirão do automóvel (esses três últimos com o propósito exclusivo de atrair público). Além disso, para o produtor, as feiras promoveram uma série de orientações, entre as quais, orientações para

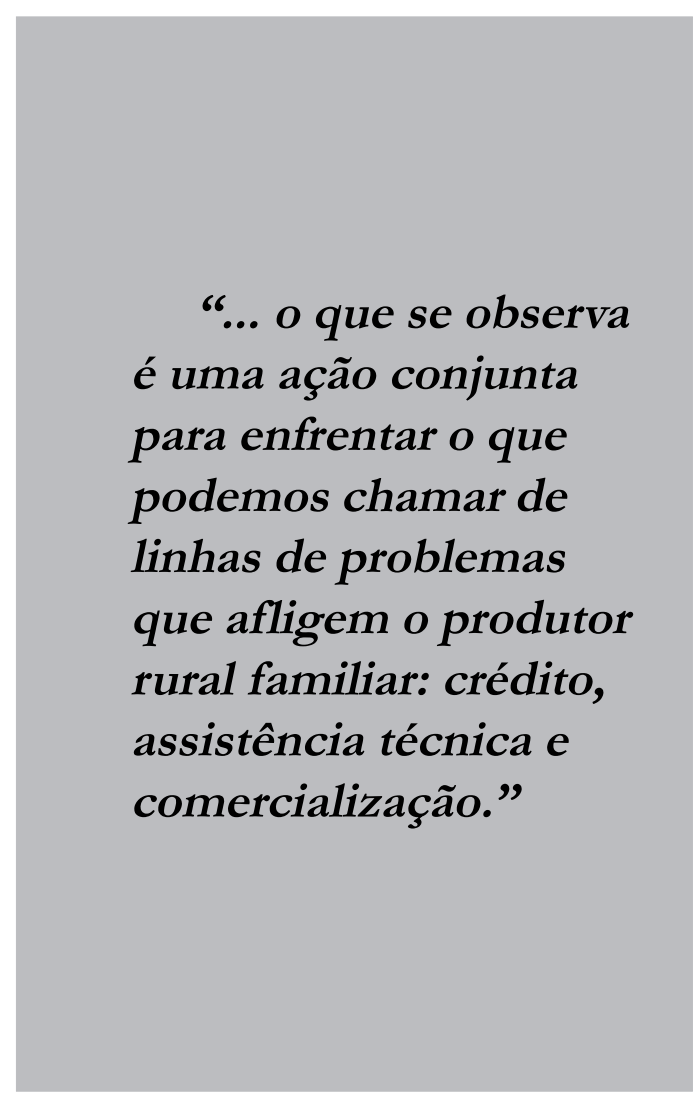

participar do Programa Compra Direta, licenciamento de granja de frango, Programa de Inseminação Artificial para Pequenos Produtores, Nota do Produtor, linhas de financiamento para produtores rurais, legalização de produtos da agroindústria familiar, Fábrica do Agricultor etc.

\section{Aprendendo com a experiência}

Apucarana foi precursora da ideia de compra direta do produtor. O Programa de Compra Direta começou quando foi 
criada a primeira vila rural de Apucarana, em meados dos anos 1990. A Prefeitura, naquela ocasião, começou a comprar produtos dos produtores rurais dessas vilas para a merenda escolar. Atualmente, a partir da Lei Federal n $11.947 / 09$, que estimula a compra direta, os produtores devem fazer um cadastramento na Emater, que avaliará a qualidade dos produtos e a quantidade que os produtores têm capacidade de entregar. Esses produtos devem ser cadastrados pela Vigilância Sanitária e devem entrar no Sistema de Inspeção Municipal (SIM).

De acordo com o Artigo 14 da Lei no 11.947/09:

Do total dos recursos financeiros repassados pelo FNDE, no âmbito do PNAE, no mínimo 30\% (trinta por cento) deverão ser utilizados na aquisição de gêneros alimentícios diretamente da agricultura familiar e do empreendedor familiar rural ou de suas organizações, priorizando-se os assentamentos da reforma agrária, as comunidades tradicionais indígenas e as comunidades quilombolas (BrasiL, Lei $\left.\mathrm{n}^{\mathrm{o}} 11.947 / 09\right)$.

Portanto, observa-se, ao comparar tal lei com a Lei Municipal de Apucarana (Lei $\mathrm{n}^{\mathrm{o}}$ 143/2006), que o Município foi precursor de tal iniciativa, e que, diferentemente da lei federal, não há um parâmetro mínimo $(30 \%)$ para consecução dos gastos.

A parceria com a Emater é fundamental para o bom desempenho de cada uma das atividades e programas desenvolvidos para o agricultor familiar, seja para facilitação do acesso ao crédito bancário, para o apoio e a qualificação técnica, seja para incorporar aspectos relativos à valorização da mulher na produção rural (política de gênero), ou para colaborar com a organização dos produtores enquanto ação coletiva.

No caso de Apucarana, além da criação do "mercado institucional", foi possível observar o fortalecimento dos circuitos curtos de produção, conectando o produtor que se apropria de forma mais plena do valor agregado no processo produtivo - com o consumidor final (comunidade escolar), a quem se garante alimentação de melhor qualidade com conhecimento de origem e procedência.

Depois dessa experiência, e como resultado de uma combinação de aprendizados com experiências locais e articulação nacional para a promoção da agricultura familiar, muita coisa foi alterada no plano nacional, dentre as quais se destacam as seguintes.

1) A criação da Lei no $12.349 / 10$, que altera $\mathrm{o}$ art. 3을 da Lei no 8.666/93. Assim, a função da licitação deixa de ser tão somente a de obter a proposta mais vantajosa, e passa a ser de promover o desenvolvimento inclusivo, de forma a direcionar a demanda do Estado para o desenvolvimento local.

2) A criação da Lei complementar $\mathrm{n}^{\circ}$ 123, de 14 de dezembro de 2006, que institui o Estatuto Nacional da Microempresa e da Empresa de Pequeno Porte. A lei dispõe, entre outras coisas, sobre a garantia de preferência por organizações associativas e inclusivas no processo de licitação. A lei também elimina etapas do processo licitatório e estabelece prazos diferenciados para as empresas enquadradas em tal situação.

3) A Lei Complementar n⿳0 123/06 institui a possibilidade de participação exclusiva das micro e pequenas empresas em licitações de até R $\$ 80$ mil, bem como dá preferência a essas empresas em face das grandes, na ocasião em que os valores forem próximos. 
4) A já citada Lei n. ${ }^{\circ} 11.947 / 2009$, segundo a qual, pelo menos $30 \%$ dos alimentos para o Programa Nacional de Merenda Escolar (PNAE), adquiridos com recursos do Fundo Nacional de Educação (FNDE), devem ser oriundos da agricultura familiar, favorecendo, assim, a produção local no processo de compras públicas. Deve-se ressaltar que, embora a lei especifique um mínimo de 30\%, esse dispositivo não funciona como impeditivo para que se compre qualquer valor superior.

\section{Considerações finais}

Ao articular a narrativa dessa experiência peculiar de Apucarana com as alterações do quadro legal observadas posteriormente, tornam-se pertinentes três observações.

1) O potencial dos pequenos Municípios em criarem políticas públicas. A experiência de Apucarana demonstra que os Municípios são capazes de criar políticas públicas para resolverem seus problemas. Nessa medida, os governos estaduais e federal devem cumprir impor- tante papel de "radar", ao atentarem para o potencial inovador das experiências que brotam nos municípios.

2) O potencial de ampliar as estratégias de compras públicas e promoção do desenvolvimento local no setor educação, por meio das compras de gêneros alimentícios, de uniforme escolar, de jogos pedagógicos, ou mesmo de formas alternativas de transporte escolar.

3) Os curiosos números mágicos. A experiência de Apucarana, além de precursora, demonstra que é possível gastar bem mais de 30\% das transferências de recursos públicos "carimbados" para alimentação escolar com os produtores locais. A experiência do Município de Conchal (SP), induzida pela lei federal, corrobora a possibilidade de gastos muito superiores aos 30\%. Então, apesar de o artigo 14 da Lei no $11.947 / 09$ não configurar um dispositivo impeditivo para compras superiores a 30\%, fica a pergunta: por que o minimum minimorum é de $30 \%$ e não um outro número mágico qualquer como $50 \%$, oxalá $70 \%$, quiçá $100 \%$ ?

(Artigo recebido em dezembro de 2012. Versão final em dezembro de 2013).

\section{Notas}

${ }^{1}$ A viagem para Apucarana foi realizada no âmbito do Prêmio Municípios que Fazem Render Mais.

${ }^{2}$ Em Apucarana, existe a primeira vila rural implementada no Estado do Paraná, como política do Governo do Estado. Chama-se Vila Rural Nova Ucrânia, foi inaugurada em 1996, e é composta por 65 propriedades com área entre $5.000 \mathrm{~m}^{2} \mathrm{e} 7.000 \mathrm{~m}^{2}$. Em Apucarana também há a Vila Rural Terra Prometida, inaugurada em 1998, e composta por 38 propriedades com área entre $5.000 \mathrm{~m}^{2}$ e $7.000 \mathrm{~m}^{2}$.

${ }^{3}$ Em 2011, o artigo 19 da Lei Federal n. ${ }^{\circ}$ 10.696, de 2 de julho de 2003, teve sua redação alterada pelo artigo 33 da Lei n ${ }^{\circ} 12.512$, de 14 de outubro de 2011. Atualmente, a previsão de 
dispensa de licitação está no artigo $5^{\circ}$ do Decreto n..$^{\circ}$ 7.775, de 04 de julho de 2012. Para maiores detalhes sobre a gênese e a trajetória da legislação que trata do Programa Nacional de Alimentação Escolar, ver: CALDAS, Eduardo de Lima; ÁVILA, Mário Lúcio. Continuidade de políticas públicas e o caso do Programa Nacional de Alimentação Escolar (PNAE). Revista Espaço Acadêmico (UEM), v. 13, p. 77-84, 2013.

\section{Referências bibliográficas}

Alves, M. M. A força do povo: democracia participativa em Lages. São Paulo: Brasiliense, 1980. São Paulo: Sementes de Democracia. São Paulo: Brasiliense, 1985.

Apucarana. Lei Municipal nº 143, de 14 de setembro de 2006. Dispõe sobre a dispensa de processo licitatório para a aquisição de produtos agropecuários produzidos por agricultores familiares e dá outras providências. Diário Oficial de Apucarana, 14 de setembro de 2006.

Apucarana. Relatório Quantitativo da Educação Integral em Apucarana. Apucarana, 20 de março de 2010.

BACATTini, G. O distrito marshalliano: uma noção socioeconômica. In: BENKO, G.; LIPIETZ, A. (Orgs.). As regiões ganhadoras. Distritos e redes: os novos paradigmas da geografia econômica. Portugal: Celta, 1994.

Benko, G.; Lipietz, A. O novo debate regional: posições em confronto. In: BenKo, G.; LipIETZ, A. (Orgs.). As regiões ganhadoras. Distritos e redes: os novos paradigmas da geografia econômica. Portugal: Celta, 1994.

Boothoroyd, Peter; Davis, H. Craig. Desenvolvimento Econômico Comunitário: três abordagens. Mimeo, s/d.

Brasil. Lei Complementar no 123, de 14 de dezembro de 2006. Institui o Estatuto Nacional da Microempresa e da Empresa de Pequeno Porte, e dá outras providências. Diário Oficial da República Federativa do Brasil, Brasília, 15 de dezembro de 2006.

Lei Federal nº 10.696, de 2 de julho de 2003. Dispõe sobre a repactuação e o alongamento de dívidas oriundas de operações de crédito rural, e dá outras providências. Diário Oficial da República Federativa do Brasil, Brasilia, 2 de julho de 2003.

. Lei $\mathrm{n}^{\mathrm{Q}}$ 11.947, de 16 de junho de 2009. Dispõe sobre o atendimento da alimentação escolar e do Programa Dinheiro Direto na Escola aos alunos da educação básica; altera as Leis nos 10.880, de 9 de junho de 2004, 11.273, de 6 de fevereiro de 2006, 11.507, de 20 de julho de 2007; revoga dispositivos da Medida Provisória no 2.178-36, de 24 de agosto de 2001, e a Lei no 8.913, de 12 de julho de 1994; e dá outras providências. Diário Oficial da República Federativa do Brasil, Brasília, 16 de junho de 2009. . Lei no 12.512 de 14 de outubro de 2011. Institui o Programa de Apoio à Conservação Ambiental e o Programa de Fomento às Atividades Produtivas Rurais; altera as Leis $\mathrm{n}^{\mathrm{o}}$ 10.696, de 2 de julho de 2003, no 10.836, de 9 de janeiro de 2004, e 
nº 11.326, de 24 de julho de 2006. Diário Oficial da República Federativa do Brasil, Brasília, 14 de outubro de 2011.

Decreto $\mathrm{n}^{\mathrm{o}}$ 7.775, de 04 de julho de 2012. Regulamenta o art. 19 da Lei no 10.696, de 2 de julho de 2003, que institui o Programa de Aquisição de Alimentos, e o Capítulo III da Lei no 12.512, de 14 de outubro de 2011, e dá outras providências. Diário Oficial da República Federativa do Brasil, Brasília, 04 de julho de 2012.

Caldas, Eduardo de Lima; Ávila, Mário Lúcio. Continuidade de políticas públicas e o caso do Programa Nacional de Alimentação Escolar (PNAE). Revista Espaço Acadêmico (UEM), v. 13, p. 77-84, 2013.

Candido Junior, J.O. Os gastos públicos no Brasil são produtivos? Brasília: IPEA, 2001 (Texto para Discussão, n. 781).

Carvalheiro, Nelson. Fundamentos da intervenção do Estado: algumas concepções em Keynes e Kalecki. Revista de Economia Política, v. 7, n. 2, p. 105-122, abril/junho, 1987.

Catanni, Antônio David e Ferrarini, Adriane Vieira. Participação, desenvolvimento local e política pública: estratégias articuladas para a superação da pobreza. Revista Katái, Florianópolis, v. 3, 2010.

Davis, H. Craig. Buy Local Programs: Import Substitution at the Regional Level. UBC Planning Paper. Canadian Planning Issues, 25. School of Community and Regional Planning. The University of British Columbia, 1987.

Dillard, Dudley. A teoria econômica de John Maynard Keynes. São Paulo: Pioneira, 1976.

Dowbor, Ladislau. Frentes de Trabalho: uma proposta que gera emprego, desenvolve infraestruturas e dinamiza o crescimento. Caros Amigos, junho, 2004.

Gomes, Vinicius P. G. \& Alves, Mário. O Programa Oportunidade Solidária e a emancipação: uma visão crítica. In: Anais do IV Encontro Internacional de Economia Solidária. São Paulo: USP, 2005.

Hirschman, Albert. O progresso em coletividade: experiências de base na América Latina. Rosslyn: Fundação Interamericana, 1984.

Keynes, John. M. A teoria geral do juro, do emprego e da moeda. 1ª ed. São Paulo: Atlas, 1982. KRugman, Paul. Um basta à depressão econômica: propostas para uma recuperação plena e real da economia mundial. Rio de Janeiro: Elsevier/Campus, 2012.

Lima, Jandir Ferrera de; e Pitaguari, Sinival Osorio. As idéias keynesianas e o crescimento do produto nas economias locais. Revista Interações, v. 6, no 10, p.11-20, mar. 2005. Martins, R. D. A.; VAZ, J. C.; Caldas, E. L. A gestão do desenvolvimento local no Brasil: (des)articulação de atores, instrumentos e território. Revista de Administração Pública, v. 44, n. 3, p. 559-90, maio/junho, 2010.

Melo, M. A. Crise federativa, guerra fiscal e "hobbesianismo" municipal: efeitos perversos da descentralização? São Paulo em Perspectiva, v. 10, n. 3, p. 11-20, 1996.

Pecqueur, Bernard. Le développement local. Paris: Syros/La Découverte, 1989.

Les territoires créateurs de nouvelles ressources productives: le cas de l'agglomération grenobloise, Géographie, économie, société, 2005/3, v. 7, p. 255-268. 
Santos, B. S.; Rodríguez-Garavito, C. A. Introduction: expanding the economic canon and searching for alternatives to neoliberal globalization. In: SANTOS, B. de S. (Org.). Another production is possible. Beyond the capitalist canon. London: Verso, 2006.

São Paulo. Governo do Estado. A Batalha da Alimentação no Governo Montoro. São Paulo, 1987.

Governo do Estado. A Batalha da Descentralização e Participação no Governo Montoro. São Paulo, 1987.

SCHOR, Sílvia Maria. Intervencionismo estatal: nova roupa para uma velha questão. São Paulo em Perspectiva, v. 2, n. 1, p. 28-29, janeiro/março, 1988.

Sebrae. Cartilha do Comprador. compras públicas alavancando o desenvolvimento. 2010.

Silveira, C.; Bocayuva, C.; Zapata, T. Ações integradas e desenvolvimento local: tendências, oportunidades e caminhos. São Paulo: Instituto Pólis, PGPC/Eaesp/ FGV, 2001.

Souza, Herbert José de. Município de Boa Esperança: participação popular e poder local. In: Moises, José Álvaro (org.). Alternativas populares da democracia: Brasil, anos 80. Rio de Janeiro: Editora Vozes; São Paulo: CEDEC, 1982.

Tendere, Judith. Bom governo nos trópicos: uma visão crítica. Rio de Janeiro: Revan; Brasília: ENAP, 1998.

Vaz, J. C.; Caldas, E. L. Desenvolvimento local e políticas territoriais. In: Encontro Nacional De Administração Pública e Governança (EnAPG), 2. Anais... São Paulo, 2006.

Yin, Robert K. Estudo de caso: planejamento e métodos. $3^{\mathrm{a}}$ ed. Porto Alegre: Bookman, 2005. 212 p. 


\section{Resumo - Resumen - Abstract}

\section{Compras públicas e promoção do desenvolvimento local}

Eduardo de Lima Caldas e Raquel Sobral Nonato

O artigo pretende apresentar as compras públicas como instrumento estratégico do desenvolvimento local a partir do estudo de caso realizado em Apucarana (PR). Para compor o trabalho, foram realizadas visitas a campo e entrevistas semiestruturadas com os atores locais envolvidos no processo. Os resultados foram interpretados sob a perspectiva da relação entre consumo e a produção local, destacando ainda os procedimentos que permitiram o surgimento dessa ação estatal. O estudo conclui que existe um alto potencial de disseminação do caso de Apucarana, sobretudo no que se refere à criação de políticas públicas municipais que incentivam a utilização das compras públicas para o desenvolvimento local, bem como são apontados os desafios que são impostos aos governos locais para a implementação da referida prática.

Palavras-chave: compras públicas; desenvolvimento local; arranjos institucionais; arranjos territoriais

\section{Compras públicas y desarrollo local}

Eduardo de Lima Caldas y Raquel Sobral Nonato

El documento tiene como objetivo presentar las licitaciones públicas como una herramienta estratégica para el desarrollo local a partir del estudio de caso realizado en Apucarana, Brasil. Para componer el trabajo se llevaron a cabo visitas de campo y entrevistas semi-estructuradas con actores locales involucrados en el proceso. Los resultados fueron interpretados desde la perspectiva de la relación entre el consumo y la producción local, destacando también los procedimientos que permitieron la aparición de esta acción del Estado. El estudio llega a la conclusión de que existe un alto potencial de propagación del caso de Apucarana, en particular en lo que respecta a la creación de políticas públicas municipales que fomenten el uso de la compra pública para el desarrollo local, así como, los retos que se imponen a los gobiernos locales para la implementación de la práctica.

Palabras clave: compras públicas; desarrollo local; arreglos institucionales; complejos territoriales

\section{Buying public and local development}

\section{Eduardo de Lima Caldas and Raquel Sobral Nonato}

The paper aims to present buying public as a strategic tool for local development from the case study conducted in the city of Apucarana, Brazil. To compose the work were performed field visits and semi-structured interviews with local actors involved in the process. The results were interpreted from the perspective of the relationship between consumption and local production, also emphasizing the procedures that allowed the emergence of this state action. The study concludes that there is a high potential for spread of this case, particularly with regard to the creation of municipal public policies that encourage the use of buying public to local development as well as the challenges that are imposed on local governments for the implementation of the practice.

Keywords: buying public; local development; institutional arrangements; territorial arrangements 


\section{Eduardo de Lima Caldas}

É bolsista de pós-doutorado da CAPES no CIRAD-França e professor no curso de Gestão de Política Públicas da EACHUSP.Contato: elcaldas@hotmail.com

\section{Raquel Sobral Nonato}

É mestranda em Administração Pública e Governo (EAESP-FGV) e bacharel em Gestão de Políticas Públicas pela Universidade de São Paulo. Contato: raquel@itsbrasil.org.br 